\title{
ESTIMATION OF THE PARAMETERS OF SOLAR CELLS FROM CURRENT-VOLTAGE CHARACTERISTICS USING GENETIC ALGORITHM
}

\author{
Suresh E. Puthanveettil ${ }^{1}$, Mengu $\mathrm{Cho}^{2}$ and Amrita Suresh ${ }^{3}$ \\ ${ }^{1}$ Solar Panel Division, ISRO Satellite Centre, Bangalore 560017, India. \\ ${ }^{2}$ Laboratory of Spacecraft Environment Interaction Engineering, Kyushu Institute of \\ Technology, Kitakyushu, Japan, 804-8550 \\ ${ }^{3}$ Birla Institute of Technology and Science Pilani- K K Birla Campus, Zuari Nagar, \\ Goa,India
}

\begin{abstract}
This paper presents a method for calculating the light generated current, the series resistance, shun resistance and the two components of the reverse saturation current usually encountered in the double diode representation of the solar cell from the experimental values of the current-voltage characteristics of the cell using genetic algorithm. The theory is able to regenerate the above mentioned parameters to very good accuracy when applied to cell data that was generated from pre-defined parameters. The method is applied to various types of space quality solar cells and sub cells. All parameters except the light generated current are seen to be nearly the same in the case of a cell whose characteristics under illumination and in dark were analyzed. The light generated current is nearly equal to the short-circuit current in all cases. The parameters obtained by this method and another method are nearly equal wherever applicable. The parameters are also shown to represent the current-voltage characteristics well.
\end{abstract}

\section{KEYWORDS}

Solar cell, current-voltage characteristics, reverse saturation current, series resistance, shunt resistance, particle radiation, genetic algorithm

\section{INTRODUCTION}

It is important to have the full characteristics of the solar cells and thus the solar array because of several reasons. Space solar arrays are optimized for end of life conditions (EOL). Since space systems require high reliability, the margins used are usually high and thus even at the end of life the solar array does not operate at maximum power point. The space array continuously undergoes irradiation by charged particles in geosynchronous orbit, low earth orbit or medium earth orbit due to trapped protons and electrons. Solar flare protons affect even the satellites that are situated away from the earth. Since the current from the array depends on where the array operates at each point in its life time, it is necessary to have a proper estimate of the full characteristics of the solar array. Sometimes, certain off-optimality for small periods is allowed in the design of the solar array so that it operates at points between the maximum power point and the open-circuit voltage. This is another reason why the 
knowledge of the full I-V characteristics of the cell is necessary for optimum design and analysis of the performance. Full I-V characteristics of solar cells are obtained from limited data by several means. Usually, the solar cell parameters like diffusion and recombination currents, light generated current, series resistance and shunt resistance are obtained from the measurements of several points on the I-V curve and then using these parameters the entire I-V curve is plotted using equations representing appropriate models. The knowledge of these parameters in itself is highly important for studying solar cells and for the design and manufacture of the solar cells. The effect of various environments like charged particle environment and the impact of solar array arcing have been seen to impact some or all of these parameters.

Diffusion current is characterized by an ideality factor equal to one and it varies with forward bias $\mathrm{Vj}$ and temperature $\mathrm{T}$ following the expression given by [1]

with forward bias $V_{j}$ and temperature $T$ following the expression given by [1]

$\mathrm{I}_{\mathrm{d}}=\mathrm{I}_{01}\left[\exp \left(\mathrm{qV}_{\mathrm{j}} / \mathrm{nkT}\right)-1\right]$

with $\mathrm{I}_{01} \propto \mathrm{T}^{3} \exp \left(-\mathrm{E}_{\mathrm{g}}(\mathrm{T}) / \mathrm{kT}\right), \mathrm{I}_{01}$ is the saturation current and $\mathrm{E}_{\mathrm{g}}$ is the energy gap of the material, $\mathrm{k}$ is the Boltzmann constant, $\mathrm{q}$ is the electronic charge and $\mathrm{n}$ is the ideality factor which is equal to 1 .

Recombination current in the space charge region (SCR) varies following the relation [1]

$\mathrm{I}_{\mathrm{rec}}=\mathrm{I}_{02}\left[\exp \left(\mathrm{qV}_{\mathrm{j}} / \mathrm{nkT}\right)-1\right]$

with $\mathrm{I}_{02} \propto \mathrm{T}^{3 / 2} \exp \left(-\mathrm{E}_{\mathrm{g}} / 2 \mathrm{kT}\right), \mathrm{n}$ is the ideality factor which is equal to 2 .

The full illuminated I-V characteristics of the solar cell using the equation (1) and (2)

can be represented as

$\mathrm{I}=\mathrm{I}_{\mathrm{L}}-\mathrm{I}_{\mathrm{d}}-\mathrm{I}_{\mathrm{rec}}-\left(\mathrm{V}_{\mathrm{j}}\right) / \mathrm{R}_{\mathrm{sh}}$

where $I_{L}$ is the light generated current. Using the above equation and $V_{j}=V+I R_{s}$, the double diode equation for the solar cell is obtained and is given by

$\mathrm{I}(\mathrm{V})=\mathrm{I}_{\mathrm{L}}-\mathrm{I}_{01}\left\{\exp \left[\left(\mathrm{V}+\mathrm{IR}_{\mathrm{s}}\right) \mathrm{K} / \mathrm{T}\right]-1\right\}-\mathrm{I}_{02}\left\{\exp \left[\left(\mathrm{V}+\mathrm{IR}_{\mathrm{s}}\right) \mathrm{K} / 2 \mathrm{~T}\right]-1\right\}-\left(\mathrm{V}+\mathrm{IR}_{\mathrm{s}}\right) / \mathrm{R}_{\mathrm{sh}}$

where $R_{s}$ is the series resistance and $R_{s h}$ is the shunt resistance of the solar cell and $\mathrm{K}$ is equal to $\mathrm{q} / \mathrm{k}$.

This double diode model has been in use for obtaining solar array currents at different voltages and intensities and aspect angles by people working in the area of solar arrays especially those in space industry. The accuracy of this model is found to lie within 1 to $2 \%$ for space quality silicon and gallium arsenide solar cells. Although this model is very attractive, the actual calculation of the two components of the reverse saturation current as well as the series resistance and shunt resistance is not easy. It is also not possible to directly apply a least squares method because of the non linear nature of the problem. This problem is compounded by the fact that we have to solve implicit equations also.

This problem has been attacked from different angles by different authors. S. Mottet[2] has given a least-square solution of the problem. Since the solar cell equation is implicit, the solution is not straightforward, but uses iteration procedure for estimating the series resistance. Sharma et. al. [3] have employed an analytical solution to the problem. However, the equations in this method are complicated and in practice, the analytical solution is not straight forward and the use of software is usually required. Another limitation of this method is that the light generated current is assumed to be equal to the short-circuit current and shunt resistance is totally neglected. Recently, Suresh Puthanveettil [4] has suggested a spread sheet solution to the problem. Even though the light generated current appears as an output, here again shunt resistance is totally neglected. 
Genetic Algorithms belong to the group of evolutionary computation methods. These are adaptive search algorithms used to tackle optimization problems. These algorithms are heuristic in nature and the search is conducted by creation of generations of solutions. The search is refined by information gained from previous generations. The fitness of each solution is computed and the final solution is based on the principle of the survival of the fittest as in Darwin's theory of evolution.

In the present paper, we employ Genetic Algorithm to solve the problem and to arrive at the parameters defined above. There are several advantages to Genetic Algorithm. One is that a full search of the solution space is not required. Another advantage is that this software can be easily adapted for a more general equation of the

form

$\mathrm{I}(\mathrm{V})=\mathrm{IL}-\mathrm{I} 01\{\exp [(\mathrm{V}+\mathrm{IRs}) \mathrm{K} / \mathrm{mT}]-1\}-\mathrm{I} 02\{\exp [(\mathrm{V}+\mathrm{IRs}) \mathrm{K} / 2 \mathrm{nT}]-1\}-(\mathrm{V}+\mathrm{IRs}) / \mathrm{Rsh}$

where $\mathrm{m}$ and $\mathrm{n}$ are new parameters which may sometimes be necessary for more accuracy. Similarly, the dark cell I-V measurement can be used directly without altering the software to estimate all parameters except the light generated current. In fact to the best of our knowledge the first use of genetic algorithm for solar cells was made by Okumura et al., [5] to obtain the parameters of solar cell under dark condition employing a single diode model of the form

$$
\mathrm{I}(\mathrm{V})=\mathrm{I}_{01}\left\{\exp \left[\left(\mathrm{V}+\mathrm{IR}_{\mathrm{s}}\right) \mathrm{K} / \mathrm{mT}\right]-1\right\}-\left(\mathrm{V}+\mathrm{IR}_{\mathrm{s}}\right) / \mathrm{R}_{\mathrm{sh}}
$$

\section{ALGORITHM}

The algorithm can be broken down into the following steps

i.Generation of initial population is done by random number generation. The number of initial population is chosen as 1000 in our case, but this number can be varied depending on the choice of the user. Each parameter like the light generated current, series resistance and so on are represented by a 16 bit binary number( The number of bits can be increased for more accuracy). This binary number is converted to decimal number and the value for each of these parameters is calculated by dividing the range of (the difference between upper and lower limits) of the variables which are chosen initially in a logarithmic fashion.

ii. The fitness of the first and other generations are calculated by comparing the I-V curve generated from the solution to the experimental values by least squares. The one where the sum of the least squares is minimum is ranked as one, the next one as two and so on.

iii. The next generation is created by choosing the parents and creating offsprings. Here we have allowed only the first $30 \%$ of the population (arranged rank wise) to

create off-springs. The off-springs are created by crossing over of the bits of the father and mother after a certain bit which is randomly chosen. We have also used the principle of elitism by retaining the first five ranks in the next generation without change.

iv. A small percentage of the bits are randomly altered (to effect mutation) so as to increase diversity.

v.The ranking, selection of parents, reproduction, selection of elites and mutation are repeated for each generation.

vi. A total of 100 generations is created and the first rank of the last generation is chosen as the fittest solution. 


\section{RESULTS AND ANALYSIS}

The first analysis we have carried out with this software is with imaginary Silicon $2 \mathrm{ohm}-\mathrm{cm}$ solar cell with the following parameters which are given in Table1.

Table 1. Input parameters for obtaining the current-voltage characteristics of a simulated solar cell

\begin{tabular}{|l|l|}
\hline Parameter & Value \\
\hline IL & $1.00 \mathrm{amp}$ \\
\hline I01 & $1 \times 10^{-10} \mathrm{amp}$ \\
\hline $\mathrm{I}_{02}$ & $5 \times 10^{-1} \mathrm{amp}$ \\
\hline $\mathrm{R}_{\mathrm{s}}$ & $0.025 \mathrm{ohm}$ \\
\hline $\mathrm{R}_{\mathrm{sh}}$ & $1000 \mathrm{ohm}$ \\
\hline
\end{tabular}

Using these parameters we have calculated the I- V characteristics of the solar cell. Using these current and voltage values as input, we have run the genetic code to get back the parameters and the results are given in Table2.

Table 2. Output parameters of the simulated solar cell of Table 1. obtained through genetic algorithm

\begin{tabular}{|l|l|}
\hline Parameter & Value \\
\hline IL & $0.9999 \mathrm{amp}$ \\
\hline I 1 & $1.1184 \times 10^{-10} \mathrm{amp}$ \\
\hline $\mathrm{I} 02$ & $4.958 \times 10^{-1} \mathrm{amp}$ \\
\hline $\mathrm{R}_{\mathrm{s}}$ & $0.02488 \mathrm{ohm}$ \\
\hline Rsh & $980 \mathrm{ohm}$ \\
\hline
\end{tabular}

From this table we understand the most of the parameters can be known very accurately if the input current and voltage values are measured properly. There is some inaccuracy as far as I01 is concerned which here is about $12 \%$. Shunt resistance inaccuracy is about $2 \%$ and all other errors are minimal. This gives an indication of the accuracy of this method of estimating the parameters given in Tables 1 and 2.

Next, we have used the developed software to analyze $10 \mathrm{ohm} \mathrm{Si} \mathrm{solar} \mathrm{cells} \mathrm{of} \mathrm{nominal}$ dimension $2 \mathrm{~cm} \mathrm{x} 4 \mathrm{~cm}$ before and after radiation to a fluence level of $3 \times 10^{13}$ electrons $/ \mathrm{cm}^{2}$. The cell types are both BSR type cells. Figure. 1 gives the I-V characteristics of unirradiated BSR cell at $28^{\circ} \mathrm{C}$. The I-V characteristics of the same cell irradiated to a fluence of $3 \times 10^{13} 1$ $\mathrm{MeVelectrons} / \mathrm{cm}^{2}$ at $28^{\circ} \mathrm{C}$ are given in Figure.2. The experimental data is represented by discrete points and the data according to our theory is presented as a continuous line in both the cases. This continuous line is generated using the parameters evaluated using genetic algorithm. In both of the above, one can notice the close match that exists between theory and experiment. It is to be noted that the experimental data were obtained by using the standard facilities and methods used in space industry.

The results of the parameters evaluated are tabulated below: 
International Journal on Soft Computing, Artificial Intelligence and Applications (IJSCAI), Vol.5, No.1, February 2016

Table 3. Output parameters of a silicon solar cell before and after electron irradiation obtained through genetic algorithm

\begin{tabular}{|l|l|l|}
\hline Parameter & Value before irradiation & Value after irradiation \\
\hline IL & $0.31819 \mathrm{amp}$ & $0.31012 \mathrm{amp}$ \\
\hline $\mathrm{I} 01$ & $8.86168 \times 10^{-11} \mathrm{amp}$ & $1.2437 \times 10^{-10} \mathrm{amp}$ \\
\hline $\mathrm{I} 02$ & $6.4422 \times 10^{-7} \mathrm{amp}$ & $9.46299 \times 10^{-7} \mathrm{amp}$ \\
\hline Rs & $0.0561 \mathrm{ohm}$ & $0.0539 \mathrm{ohm}$ \\
\hline Rsh & $531.8 \mathrm{ohm}$ & $632.4 \mathrm{ohm}$ \\
\hline
\end{tabular}

It is seen that the light generated current decreases, I01 and I02 both increase as expected. There is no remarkable change in series resistance and we believe that the apparent increase in shunt resistance also is due to the limitations of the model or method rather than a real increase in shunt resistance.

Further, we have compared the dark and illuminated characteristics of a silicon solar cell and the result is given in Table below.

Table 4. Output parameters of a silicon solar cell in dark and under illumination obtained through genetic algorithm

\begin{tabular}{|l|l|l|}
\hline Parameter & Value for cell not illuminated & Value for illuminated cell \\
\hline IL & $1 \mathrm{e}-20 \mathrm{amp}$ & $1.0690 \mathrm{amp}$ \\
\hline $\mathrm{I} 01$ & $1.4329 \times 10^{-10} \mathrm{amp}$ & $1.3395 \times 10^{-10} \mathrm{amp}$ \\
\hline $\mathrm{I} 02$ & $3.1619 \times 10^{-7} \mathrm{amp}$ & $4.869 \times 10^{-7} \mathrm{amp}$ \\
\hline Rs & $0.025148 \mathrm{ohm}$ & $0.023355 \mathrm{ohm}$ \\
\hline Rsh & $447.2 \mathrm{ohm}$ & $945.2 \mathrm{ohm}$ \\
\hline
\end{tabular}

There is a good match between the two values of I01 and Rs. Both the values of I02 are comparable, but not quite identical. The differences can be due to measurement inaccuracy and the limitations of the model.

We have also used the developed software to analyze the following types of solar cells and the results are given below.

i. GaInP solar cells

ii. (In)GaAs solar cells

iii.Ge solar cells

Table 5. Output parameters of a GaInP solar cell in under illumination obtained through genetic algorithm

\begin{tabular}{|l|l|}
\hline Parameter & Value \\
\hline Isc(measured value) & $0.50798 \mathrm{amp}$ \\
\hline Voc(measured value) & $1.3961 \mathrm{~V}$ \\
\hline IL & $0.508875 \mathrm{amp}$ \\
\hline I01 & $1.9989 \times 10^{-25} \mathrm{amp}$ \\
\hline I02 & $9.87147 \times 10^{-13} \mathrm{amp}$ \\
\hline Rs & $0.043591 \mathrm{ohm}$ \\
\hline Rsh & $192.7 \mathrm{ohm}$ \\
\hline
\end{tabular}


International Journal on Soft Computing, Artificial Intelligence and Applications (IJSCAI), Vol.5, No.1, February 2016

Table 6. Output parameters of an (In)GaAs solar cell in under illumination obtained through genetic algorithm

\begin{tabular}{|c|c|}
\hline Parameter & Value \\
\hline Isc(measured value) & $0.55074 \mathrm{amp}$ \\
\hline Voc(measured value) & $1.0305 \mathrm{~V}$ \\
\hline IL & $0.5505 \mathrm{amp}$ \\
\hline $\mathrm{I} 01$ & $2.359 \times 10^{-10} \mathrm{amp}$ \\
\hline $\mathrm{I} 02$ & $3.5898 \times 10^{-10} \mathrm{amp}$ \\
\hline $\mathrm{R}_{\mathrm{s}}$ & $0.053179 \mathrm{ohm}$ \\
\hline $\mathrm{R}_{\mathrm{sh}}$ & $9999 \mathrm{ohm}$ \\
\hline
\end{tabular}

Table 7. Output parameters of a Ge solar cell in under illumination obtained through genetic algorithm

\begin{tabular}{|l|l|}
\hline Parameter & Value \\
\hline Isc(measured value) & $0.84733 \mathrm{amp}$ \\
\hline Voc(measured value) & $0.2474 \mathrm{~V}$ \\
\hline IL & $0.85929 \mathrm{amp}$ \\
\hline $\mathrm{I}_{01}$ & $2.766 \times 10^{-5} \mathrm{amp}$ \\
\hline $\mathrm{I}_{02}$ & $4.4109^{-} \times 10^{-5} \mathrm{amp}$ \\
\hline $\mathrm{R}_{\mathrm{s}}$ & $0.02306 \mathrm{ohm}$ \\
\hline $\mathrm{R}_{\mathrm{sh}}$ & $199.98 \mathrm{ohm}$ \\
\hline
\end{tabular}

The three cells mentioned above comprise the sub-cells of triple junction solar cells usually used in the space industry. In all the cases, it is seen that the light generated current is nearly equal to the short circuit current as expected.

Next, we have compared the results of the parameters generated by the method of Puthanveettil to the method employing genetic algorithm. It can be seen that there is very good agreement between the parameters estimated by both methods wherever applicable.

Table 8. Output parameters of a silicon solar cell under illumination obtained through the spread sheet method and through genetic algorithm

\begin{tabular}{|l|l|l|}
\hline Parameter & Puthanveettil & Genetic algorithm \\
\hline IL & $0.3180 \mathrm{amp}$ & $0.3182 \mathrm{amp}$ \\
\hline I01 & $8.106 \times 10^{-11} \mathrm{amp}$ & $8.862 \times 10^{-11} \mathrm{amp}$ \\
\hline I02 & $7.034 \times 10^{-1} \mathrm{amp}$ & $6.442 \times 10^{-1} \mathrm{amp}$ \\
\hline $\mathrm{R}_{\mathrm{s}}$ & $0.0626 \mathrm{ohm}$ & $0.0561 \mathrm{ohm}$ \\
\hline Rsh & infinite & $531.8 \mathrm{ohm}$ \\
\hline
\end{tabular}

The last question which we addressed is the utility of genetic algorithm on the reproduction of the current voltage characteristics of the solar cells. In all the cells which we have carried out the study, the results show a very good match between the measure values and the values estimated from the parameters like I01 and I02 which we have obtained using genetic algorithm. An example is given in Figure 1 for a silicon BSR solar cell. 


\section{CONCLUSION}

A method of calculating the solar cell parameters like the two different components of the reverse saturation current and the series resistance, the shunt resistance and the light generated current was developed using genetic algorithm applied to the experimental current voltage characteristics of the cell. The data obtained were physical and the variations seen in the parameters due to irradiation were as expected in the silicon solar cell. Similarly, the parameters except the light generated current did not vary much when the illuminated and dark cell characteristics of the same silicon cell were analyzed using genetic algorithm. The algorithm was used to analyze other types of cells and there was very close match between values generated by genetic algorithm and by another method proposed by Puthanveettil. The algorithm was applied to get back the solar cell parameters from the characteristics of an ideal cell which was generated using the solar cell equation from the solar cell parameters and the reproduction of values was seen to be very good. There was close match between the current-voltage characteristics generated from the parameters obtained by genetic algorithm and the original experimental values. All these point to the adequacy of genetic algorithm to obtain the solar cell parameters.

\section{REFERENCES}

[1] H.Y. Tada, J. R. Carter, B. E. Anspaugh and R. G. Downing, "Solar cell radiation handbook", JPL Publication 82-69

[2] S.Mottet,"Solar cell modellng for computer-aided design and irradiation degradation of generators", Photovoltaic generators in space, ESA-SP-147, Heidelberg, 1980.

[3] S. K. Sharma, D. Pavithra, N. Srinivasamurthy and B. L. Agarwal, "Determination of solar cell parameters: an analytical approach", Journal of Physics D: Applied Physics, PP. 1130-1133, Vol. 26, 1993.

[4] Suresh Puthanveettil, "Prediction of full current-voltage characteristics of space silicon solar cells from limited data by using a spreadsheet function", Journal of Spacecraft Technology, Vol22,No2, pp01-06,June 2012

[5] Teppei Okumura, Shunichiro Ninomiya, Hirokazu Masui, Kazuhiro Toyoda, Mitsuru Imaizumi, Mengu Cho, 'Solar cell degradation due to ESD for international standardization of solar array ESD test' Proceedings of 10th Spacecraft Charging Technology Conference, published in CD, 2007, Biarritz, France

\section{AUTHORS}

Suresh E. Puthanveettil obtained his Master's Degree in Physics from Brooklyn College of the City University of New York where he was also teaching Physics and Astronomy. After a brief stint as a lecturer in Physics with the Regional Engineering College, Calicut (now National Institute of Technology), he joined the Solar Panel Division of ISRO Satellite Centre, where he has been working for the last 29 years. Presently he is Head of Solar Panel Division. His areas of major interest are solar panel design, fabrication and testing, particle radiation estimation of satellites in general and solar panels in particular

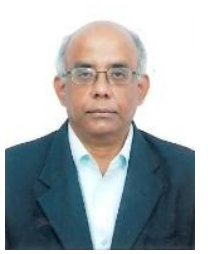
and electrostatic discharge on solar panels. He has been invited to give talks on his work both in India and abroad by educational institutions. He has guided several Master of Computer Application students for their projects. He has translated 'Gita Sadhana-a Samvit Stair-case', a book of great erudition in practical Vedanta, from Hindi to English. 
Mengu Cho received the B.S. and M.S. degrees from the Department of Aeronautics and Astronautics, University of Tokyo, in 1985 and 1987, respectively, and the Ph.D. degree from the Department of Aeronautics and Astronautics, Massachusetts Institute of Technology, the United States of America, in 1992. From 1992 to 1995, he was a Research Associate with Kobe University, Japan. From 1995 to 1996, he was a Teaching Associate with International Space University, France. Since 1996, he has been with the Department of Electrical Engineering and Electronics, Kyushu Institute of Technology,

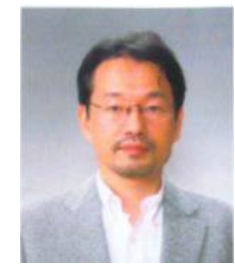
where he was an Assistant Professor in 1996 and an Associate Professor in 1997 and has been a Professor and also the Director of the Laboratory of Spacecraft Environment Interaction Engineering since 2004. He has been with the Department of Applied Science for Integrated system engineering since 2010. His research interest is spacecraft environment interaction, especially spacecraft charging, and small satellite systems engineering.

Amrita Suresh is currently pursuing her Bachelor's Degree in Computer Science from BITS Pilani K K Birla Goa Campus. She is doing her thesis at IIT Bombay, in Parallel Algorithms and Circuit Complexity. She briefly interned with Intuit India, and worked in the QuickBooks Development Team. She also interned in the Indian Space Research Organization, in the Power Systems Group. Her research interests are Theory of Computation, Algorithms, and Complexity Theory.

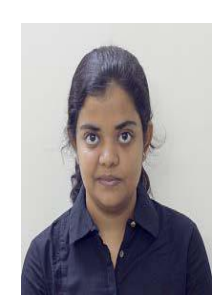

